\title{
Las cofradías de Alcalá de Guadaíra a fines de la Edad Media
}

Juan Carlos Arboleda Goldaracena

Universidad Pablo de Olavide (España) 



\title{
Las cofradías de Alcalá de Guadaíra a fines de la Edad Media
}

\section{Confraternities in Alcalá de Guadaíra at the end of the Middle Ages}

\author{
Juan Carlos Arboleda Goldaracena \\ Universidad Pablo de Olavide (España) \\ jcarbgol@upo.es
}

Fecha de recepción: 23 de octubre de 2017

Fecha de aceptación: 23 de diciembre de 2018

\begin{abstract}
Resumen
En el presente trabajo abordamos, a partir de la documentación notarial, el estudio de las distintas cofradías existentes en Alcalá de Guadaíra (Sevilla) a finales de la Edad Media. Estudiamos las advocaciones bajo las que estaban erigidas, su composición, sus órganos de gobierno y las propiedades en las que basaban su vida económica. A pesar de la escasez de datos que ofrecen para la época estudiada, los protocolos notariales son prácticamente la única documentación disponible para el acercamiento al tema.
\end{abstract}

Palabras clave: Cofradías; Alcalá de Guadaíra (Sevilla); Reino de Sevilla; Religiosidad; Edad Media.

\begin{abstract}
In this paper we aim to know the confraternities present in Alcalá de Guadaíra (Seville, Spain) at the end of the Middle Ages using notarial documentation. We study their devotions, their social composition, their administration and their properties and economic resources. Although notarial documentation does not offer many information in the case of Late Middle Ages, it is almost the only source in order to study confraternities during this period.
\end{abstract}

Keywords: Confraternities; Alcalá de Guadaíra (Seville, Spain); Kingdom of Seville; Religiousness; Middle Ages.

Para citar este artículo: Arboleda Goldaracena, J. C. (2019). Las cofradías de Alcalá de Guadaíra a fines de la Edad Media. Revista de humanidades, n. 36, pp. 11-31. ISBN 1130-5029 (ISSN-e 2340-8995).

Sumario: 1. Introducción. 2. Las cofradías documentadas: sus advocaciones. 3. El gobierno de las cofradías. Los cofrades. 4. Las propiedades de las cofradías. 5. Conclusiones. 6. Bibliografía. 


\section{INTRODUCGIÓN}

Alcalá de Guadaíra ${ }^{1}$, situada a escasos $17 \mathrm{~km}$. de la capital sevillana, ha constituido desde siempre un importante núcleo poblacional dentro del territorio hispalense. Conquistada por Fernando III en torno a 1246-1247 como parte de la campaña de asedio a la capital, Alcalá se convirtió enseguida en puerta de acceso y bastión defensivo de Sevilla. Su término municipal fue protagonista de numerosas donaciones hechas por Alfonso X a los repobladores de la capital y registradas en el repartimiento de Sevilla, lo que explica la pronta vinculación jurisdiccional de la villa con respecto a la urbe, aparte del hecho de que esta última dependiera en muchos aspectos de Alcalá para su abastecimiento a través del agua, los molinos y el pan. En septiembre de 1258, el rey Sabio entrega la villa y el castillo de Alcalá a la Iglesia hispalense como parte del proceso de dotación de esta, aunque unos años después esta vuelve a estar bajo la jurisdicción del concejo. Todo lo cual justifica la estrecha relación de la villa alcalareña con la capital hispalense, tanto en el plano político como en el espiritual, por lo que el estudio de sus realidades sociales y religiosas es clave y puede aportar muchos datos importantes no solo a nivel local sino para el conjunto de la cercana capital y del reino de Sevilla.

En cuanto al tamaño de la población durante el período bajomedieval, el estudio de los padrones fiscales conservados en el Archivo municipal hispalense aporta datos comprendidos entre los años 1426 y 1519. En este primer año, el número de vecinos era de 137, ascendiendo a 927 a finales de la segunda década del siglo XVI, aunque con un descenso acusado durante las décadas centrales del siglo XV (Franco Silva, 1987, p. 54). La equivalencia en número de habitantes reales nos da unas cifras de más de 4000 personas a principios del siglo XVI (Franco Silva, 1987, p. 55). Alcalá contaba en la Edad Media con cuatro parroquias con sus correspondientes collaciones: Santa María (Rodríguez Baltanás, 1999), San Miguel (Romero Gutiérrez, 2001; Flores, 1833, vol. II, pp. 32-35), San Sebastián (Flores, 1833, vol. III, pp. 21-36) y Santiago (Ruiz Portillo, 2011; Flores, 1833, vol. III, pp. 3-21).

Hace ya bastantes años, el profesor Alfonso Franco publicaba un estudio sobre las propiedades de diversas instituciones eclesiásticas de Alcalá de Guadaíra en los compases finales del período medieval (Franco Silva, 1974). En concreto, y utilizando la documentación procedente del Archivo arzobispal de Sevilla y del fondo de protocolos notariales de Alcalá, el trabajo abordaba los bienes de las distintas capellanías, la fábrica de dos de las parroquias alcalareñas (Santa María y Santiago) y finalmente algunos de los monasterios, hospitales y cofradías existentes en la ciudad. Con respecto a estas últimas, únicamente se ocupaba de dos de ellas,

1 Para un estudio de su historia durante el período bajomedieval pueden consultarse las siguientes referencias: Franco Silva, 1987, 1995; González Jiménez, 1987; Fernández Gómez 2004, 2007; García Martínez, 1998, 2000a, 2000b; García Rivero, 1997; González Moreno, 1986; Jiménez Rodríguez, 2000. Aunque la historiografía alcalareña anterior al siglo XX es escasa, hemos de destacar el trabajo del padre Flores, que aporta bastantes datos referidos a los aspectos religiosos: Flores, 1833. 
reseñando brevemente algunas de sus propiedades. La consulta de los fondos notariales de Alcalá, conservados en el Archivo Histórico Provincial de Sevilla, permite, no obstante, completar aún más el panorama referente a la vida de las cofradías alcalareñas. Es lo que pretendemos hacer en este trabajo ${ }^{2}$. A pesar de que el conjunto de noticias sobre estas instituciones en la Alcalá bajomedieval es escaso, podemos extraer datos significativos sobre su presencia y funcionamiento, datos que además es posible contrastar con los de otras localidades del reino de Sevilla, como la propia capital o Jerez de la Frontera, para obtener una visión no centrada en el localismo sino abierta a conclusiones más generales. Nuestro estudio, por tanto, trata de llenar un hueco en la historiografía local, completando trabajos anteriores, pero con vocación de poner en relación estos datos con lo que sucedía al menos en el resto del reino de Sevilla.

Definimos las cofradías de los siglos XIII a comienzos del XVI (Sánchez Herrero, 1985, 1988, 1995, 1996, 1999, 2003, en línea; Sánchez Herrero y Pérez González, 1999; Martín-Viveros Tajuelo, 2012; Navarro Espinach, 2014) como asociaciones preferentemente de laicos, hombres y mujeres, que se unen para diversos fines, siempre teniendo como marco el de una vida cristiana según las enseñanzas evangélicas (Sánchez Herrero, 2003, pp. 21-22). En Andalucía están presentes desde los años inmediatamente posteriores a la conquista castellana. En función del fin o fines para los que surgen, podríamos distinguir entre cofradías devocionales (para dar culto a Dios, la Virgen, un santo...), cofradías benefactoras (para ejercer la caridad intra o extra corporativa), cofradías profesionales, cofradías de clérigos, cofradías agrupación de personas pertenecientes a un mismo grupo social, o cofradías agrupación de disminuidos físicos, todas ellas con el fin de unir a diversos grupos humanos para la defensa o práctica de sus intereses comunes, ya sean profesionales o religiosos (Pérez González, 2005, pp. 123-132).

El uso de la documentación notarial para el acercamiento a las cofradías alcalareñas bajomedievales no es casual: se trata prácticamente de la única documentación conservada referente al período objeto de nuestro estudio. Por desgracia, para nuestro caso en particular y el del reino de Sevilla en general, la documentación referente a hermandades y cofradías custodiada en los riquísimos fondos del Archivo arzobispal se remonta a finales del XVI. También comienzan a finales de este siglo las series más o menos completas de documentos conservados en los archivos de las propias hermandades, entre los que se encuentran los libros de registros de hermanos o de acuerdos de cabildos, fundamentales para conocer la vida cofrade (Rodríguez Mateos y López Gutiérrez, 2000). Esto hace que tengamos que recurrir a la documentación notarial para obtener datos referentes a siglos anteriores, si bien en la mayoría de las ocasiones no son demasiado abundantes y la información que aportan muchas veces es indirecta debido a la propia naturaleza de

2 La localización y consulta de los documentos ha sido posible gracias al trabajo de García Díaz, 2010. 
los documentos, que dan cuenta de las relaciones de las cofradías con la sociedad y no propiamente de su vida interna ${ }^{3}$. Aun así, se trata de una tipología documental que hay que tener en cuenta y que ha dado muy buenos resultados en el estudio de esta realidad en otras localidades del reino de Sevilla (Pérez González, 2005, 2016).

\section{LAS GOFRADÍAS DOCUMENTADAS: SUS ADVOCACIONES}

Ofrecemos en primer lugar una relación completa de las cofradías documentadas a partir de los protocolos notariales, con sus sedes en caso de conocerlas. Son siete:

- Cofradía del Cuerpo de Dios. Se documenta por primera vez en $1478^{4}$. Aunque no se menciona su sede suponemos que se trata de la parroquia de Santa María por las casas que la cofradía poseía en dicha collación, como veremos más adelante.

- Cofradía de San Sebastián. Pensamos que se trata de la misma que el profesor Franco menciona como cofradía de la Misericordia (Franco Silva, 1974). El padre Flores afirma que en la iglesia de San Sebastián había un cuadro de este santo que pintó Francisco Pacheco para el hospital del mismo nombre en el que "hay una célebre cofradia de misericordia que hace muchas obras de piedad" (Flores, 1833, vol. III, p. 30). Se documenta por primera vez en $1503^{5}$.

- Cofradía de Santa María de la Candelaria, documentada por primera vez en $1503^{6}$.

- Cofradía del Santo Espíritu, documentada por primera vez en 15037. El padre Flores la sitúa en la iglesia de Santiago (Flores, 1833, vol. III, p.17).

- Cofradía de Santa Catalina, en la ermita del mismo nombre, dedicada a la santa de Alejandría y no a la de Siena como a veces se ha afirmado. Se documenta por primera vez en $1505^{8}$.

3 Para un conocimiento profundo de la vida interna de las cofradías es necesario acudir al estudio de sus reglas o estatutos. Para el caso andaluz contamos con dos recopilaciones de reglas, con un total de más de doscientas, aunque en ninguna de ellas aparecen documentos referidos a Alcalá de Guadaíra. Véase: Sánchez Herrero y Pérez González, 2002 y Pérez González y Arboleda Goldaracena, 2017.

4 Oficio de Fernando García de Trigueros, 1 de junio de 1478. Archivo Histórico Provincial de Sevilla, sección Protocolos, Alcalá de Guadaíra, leg. 1544 PB, s.f.

5 Oficio de Silvestre de Montemayor, 11 de junio de 1503. AHPS, sección Protocolos, Alcalá de Guadaíra, leg. 1544 PB, s.f.

6 Oficio de Silvestre de Montemayor, 11 de febrero de 1503. AHPS, sección Protocolos, Alcalá de Guadaíra, leg. 1544 PB, s.f.

7 Oficio de Silvestre de Montemayor, 13 de julio de 1503. AHPS, sección Protocolos, Alcalá de Guadaíra, leg. 1544 PB, s.f.

8 Oficio de Silvestre de Montemayor, 5 de octubre de 1505. AHPS, sección Protocolos, Alcalá de Guadaíra, leg. 1544 PB, s.f. 
- Cofradía de San Bartolomé, con sede en la iglesia de Santiago. Se documenta por primera vez en $1507^{9}$.

- Cofradía de San Miguel, documentada por primera vez en $1507^{10}$. Según el padre Flores tenía su sede en la iglesia del mismo nombre (Flores, 1833, vol. II, p. 34).

La escasez de datos en la documentación nos impide conocer con certeza la tipología de cada corporación en función de los fines para los que fueron erigidas. No obstante, y en el plano cultual, sus títulos nos indican las preferencias devocionales de los cofrades: de las siete cofradías dos están dedicadas a Dios (Cuerpo de Cristo y Santo Espíritu), una a la Virgen María (Santa María de la Candelaria) y las otras cuatro a distintos santos y santas (san Sebastián, san Bartolomé, san Miguel y santa Catalina).

La devoción al Cuerpo de Dios o Jesús Sacramentado era primordial dentro del espectro devocional de los cofrades y los laicos en general a fines de la Edad Media (Arboleda Goldaracena, 2016). No en vano ya desde el siglo XV la fiesta del Corpus Christi constituía una de las grandes conmemoraciones cristianas celebrada con todo prestigio en la Península Ibérica (Sánchez Herrero, 1989, pp. 277-278; Romero Abao, 1989; Pérez González, 2003). En Sevilla, las cofradías, ya fueran sacramentales o no, realizaban en su fiesta una procesión solemne para llevar el Santísimo a los enfermos (Arboleda Goldaracena, 2016). La devoción al Espíritu Santo también estaba muy arraigada, aunque en menor proporción con respecto a las otras dos personas de la Trinidad. Las cofradías sevillanas celebraban su fiesta en Pentecostés y acudían a su inspiración mediante las misas del Espíritu Santo, sobre todo al comienzo de sus cabildos o reuniones (Arboleda Goldaracena, 2016; Pérez González, 2005, p. 45).

La devoción mariana ha sido siempre una característica singular dentro de la religiosidad popular en general y la andaluza en particular. El caso de Alcalá no es una excepción y encontramos cómo en ella, sin ir más lejos, la primera parroquia de la localidad estaba dedicada a Santa María, algo bastante frecuente en las nuevas poblaciones conquistadas por los castellanos en Andalucía a partir del siglo XIII. La única cofradía mariana documentada se nos presenta además bajo una de las advocaciones más populares en la época, la de Santa María de la Candelaria, equivalente a la fiesta o advocación de la Purificación de la Virgen o Presentación de Jesús en el Templo, celebrada el 2 de febrero (Pérez González, 2005, p. 46), y que constituía una de las cinco grandes fiestas marianas en la Edad Media, junto con la Encarnación, la Expectación, la Asunción y la Natividad (Sánchez Herrero, 1992, p. 284).

9 Oficio de Silvestre de Montemayor, 20 de junio de 1507. AHPS, sección Protocolos, Alcalá de Guadaíra, leg. 1544 PB, s.f.

10 Oficio de Silvestre de Montemayor, 26 de septiembre de 1507. AHPS, sección Protocolos, Alcalá de Guadaíra, leg. 1544 PB, s.f. 
Con respecto a los santos, la veneración que recibían dentro del marco de la religiosidad bajomedieval era también muy amplia, destacando sobre todo la gran diversidad de ellos (Pérez González, 2006). En nuestro caso documentamos tres santos y una santa. En el caso de dos de los santos (san Sebastián y san Miguel), coinciden con los titulares de dos de las parroquias alcalareñas, por lo que su devoción debió ser grande. San Sebastián era muy venerado a finales de la Edad Media como abogado contra la peste y en Sevilla capital llegó a contar con seis cofradías (Pérez González, 2005, p. 54). En Jerez contaba con una (Pérez González, 2016). San Miguel era el encargado de la lucha contra el diablo y contó en la capital con cinco cofradías (Pérez González, 2005, pp. 59-60). También san Bartolomé y santa Catalina fueron protagonistas de una veneración importante por parte de los habitantes del reino de Sevilla en la época estudiada, sobre todo en el caso de la santa, que contaba en la urbe con seis cofradías a ella dedicadas (Pérez González, 2005, p. 63).

\section{EL GOBIERNO DE LAS COFRADÍAS. LOS COFRADES}

Al ser testigos de los asuntos más mundanos de las cofradías, los protocolos notariales permiten conocer quiénes eran algunos de sus miembros, sobre todo aquellos que ostentaron determinados cargos en virtud de los cuales ejercían la representación de la cofradía ante el notario para realizar diversos trámites. Aunque los datos obtenidos a raíz de la escasa documentación no son muy abundantes, podemos conocer en líneas generales, y en relación con otros casos, cómo era el panorama alcalareño en este sentido.

Sabemos por otros estudios (Arboleda Goldaracena, 2012; Pérez González, 2005, pp. 133-142; Pérez González, 2016) que las juntas de gobierno que regían las hermandades y cofradías andaluzas en la Baja Edad Media eran bastante simples, con un máximo de cinco miembros, y no había una homogeneidad en cuanto a la composición de estas juntas, variando mucho de unas cofradías a otras. En líneas generales, destaca siempre la presencia de una figura central que puede tomar varios nombres (provisor, hermano mayor, prioste, alcalde, prior, mayordomo) y que es quien lleva principalmente las riendas de la cofradía. Esta variedad de denominaciones da lugar a que en algunas cofradías se pueda documentar la presencia a la vez de varias de estas figuras, con atribución de diversas funciones para cada una de ellas. Junto a esta figura central encontramos un máximo de cuatro cargos adicionales, que pueden recibir la denominación genérica de diputados o bien adoptar cualquiera de los nombres ya indicados. También es frecuente encontrar dos figuras externas a las juntas de gobierno pero que ejercían un papel fundamental: el escribano, que tomaba nota de todos los acuerdos adoptados en las reuniones de las cofradías; y el muñidor, encargado de llamar a cada uno de los cofrades para que acudieran a las distintas actividades y celebraciones. La profesora Pérez González afirma que aquellas cofradías más evolucionadas eran las que contaban con un alcalde, un 
diputado, un hermano mayor, un prioste y un mayordomo (Pérez González, 2016). Sabemos por los estudios de esta misma profesora que en el caso de Sevilla capital la figura principal era normalmente la del prioste (Pérez González, 2005, pp. 135138), mientras que en Jerez este protagonismo era ocupado por el hermano mayor (Pérez González, 2016). El caso alcalareño, por su evidente proximidad, coincide plenamente con el de la capital sevillana: en las siete cofradías estudiadas hemos podido identificar a su prioste o preboste, que es quien representa a la cofradía en la realización de sus gestiones ante notario como principal cargo de esta ${ }^{11}$. Referimos sus nombres:

- Cofradía del Cuerpo de Dios: Juan Romero en $1478^{12}$ y Alonso Fernández de Consuegra en $1503^{13}$.

- Cofradía de San Sebastián: Pedro Martínez Gallego en $1503^{14}$.

- Cofradía de Santa María de la Candelaria: Juan de Maguilla en $1503^{15}$ y Martín Fernández de Almario en $1510^{16}$.

- Cofradía del Santo Espíritu: Alonso Fernández de Consuegra en $1508^{17}$.

- Cofradía de Santa Catalina: Alonso Rodríguez en $1505^{18}$.

- Cofradía de San Bartolomé, con sede en la iglesia de Santiago: Juan Sánchez Delicado en $1507^{19}$.

- Cofradía de San Miguel: Antón Sánchez de Alvar Sánchez en $1507^{20}$.

Los documentos referentes a las cofradías no nos indican los oficios ni procedencia social de estos priostes, si bien la consulta del fondo notarial alcalareño permite encontrar otras referencias indirectas a estas personas: Juan Romero, prioste

11 Desgraciadamente la documentación no ofrece información sobre otros cargos.

12 Oficio de Fernando García de Trigueros, 1 de junio de 1478. AHPS, sección Protocolos, Alcalá de Guadaíra, leg. 1544 PB, s.f.

13 Oficio de Silvestre de Montemayor, 24 de julio 1503. AHPS, sección Protocolos, Alcalá de Guadaíra, leg. 1544 PB, s.f.

14 Oficio de Silvestre de Montemayor, 11 de junio de 1503. AHPS, sección Protocolos, Alcalá de Guadaíra, leg. 1544 PB, s.f.

15 Oficio de Silvestre de Montemayor, 19 de febrero de 1503. AHPS, sección Protocolos, Alcalá de Guadaíra, leg. 1544 PB, s.f.

16 Oficio de Diego de Mairena, 10 de marzo de 1510. AHPS, sección Protocolos, Alcalá de Guadaíra, leg. 1094 PB, ff. 172v-173r.

17 Oficio de Silvestre de Montemayor, 24 de julio de 1508. AHPS, sección Protocolos, Alcalá de Guadaíra, leg. 1544 PB, s.f.

18 Oficio de Silvestre de Montemayor, 5 de octubre de 1505. AHPS, sección Protocolos, Alcalá de Guadaíra, leg. 1544 PB, s.f.

19 Oficio de Silvestre de Montemayor, 20 de junio de 1507. AHPS, sección Protocolos, Alcalá de Guadaíra, leg. 1544 PB, s.f.

20 Oficio de Silvestre de Montemayor, 26 de septiembre de 1507. AHPS, sección Protocolos, Alcalá de Guadaíra, leg. 1544 PB, s.f. 
de la cofradía del Cuerpo de Dios, era jurado del Concejo de Alcalá ${ }^{21}$. Alonso Fernández de Consuegra, además de ocupar el cargo de prioste en dos cofradías diferentes (Cuerpo de Dios y Santo Espíritu), era fiel de la alcabala de la carne del Concejo ${ }^{22}$. Por otro lado, Juan Sánchez Delicado, prioste de la cofradía de San Bartolomé, fue regidor del concejo alcalareño ${ }^{23}$.

En cuanto a sus cualidades, suponemos que el hecho de ocupar el cargo estaba relacionado con un determinado prestigio vital y un reconocimiento notable por parte del resto de cofrades que pudieran garantizar el éxito en el desempeño de sus labores. Esto podía ser extensible al resto de su vida, como en el caso de Pedro Martínez Gallego, prioste de la cofradía de San Sebastián, que actuó como fiador en el cobro de la renta del almojarifazgo de la villa ${ }^{24}$. También documentamos el caso de Juan de Maguilla, prioste de la cofradía de Santa María de la Candelaria, al que diversas personas - entre ellos el mayordomo de la fábrica de la iglesia de Santa María- otorgaron poderes generales para obrar en su nombre en distintos asuntos económicos ${ }^{25}$. O el de Martín Fernández de Almario, de la misma cofradía, que actuó como albacea testamentario según disposición de la testadora ${ }^{26}$. Juan Sánchez Delicado, prioste de la cofradía de San Bartolomé, fue designado como tutor de varios menores y en su nombre arrendó unas casas en Gandul, pedanía de Alcalá de Guadaíra $^{27}$, además de actuar como albacea testamentario ${ }^{28}$. A veces eran los priostes los que otorgaban poderes generales a otras personas para que actuaran en nombre de la cofradía ${ }^{29}$.

Con respecto al resto de cofrades, únicamente en tres de las cofradías hemos podido documentar un listado de miembros que acudieron al notario para otorgar poder general a sus priostes en los dos primeros casos o para reconocer al

21 Oficio de Fernando García de Trigueros, 1 de junio de 1478. AHPS, sección Protocolos, Alcalá de Guadaíra, leg. 1544 PB, s.f.

22 Oficio de Silvestre de Montemayor, 6 de julio de 1503. AHPS, sección Protocolos, Alcalá de Guadaíra, leg. 1544 PB, s.f.

23 Oficio de Diego de Mairena, 12 de noviembre de 1509. AHPS, sección Protocolos, Alcalá de Guadaíra, leg. 772 PB, "Escrituras del Concejo", s.f.

24 Oficio de Silvestre de Montemayor, 9 de marzo de 1503. AHPS, sección Protocolos, Alcalá de Guadaíra, leg. 1544 PB, s.f.

25 Oficio de Silvestre de Montemayor, 6 de julio de 1503, 29 de noviembre y 2 de diciembre de 1507. AHPS, sección Protocolos, Alcalá de Guadaíra, leg. 1544 PB, s.f.

26 Oficio de Silvestre de Montemayor, 28 de marzo de 1508. AHPS, sección Protocolos, Alcalá de Guadaíra, leg. 1544 PB, s.f.

27 Oficio de Silvestre de Montemayor, 17 de julio de 1507. AHPS, sección Protocolos, Alcalá de Guadaíra, leg. 1544 PB, s.f.

28 Oficio de Diego de Mairena, 30 de octubre de 1510. AHPS, sección Protocolos, Alcalá de Guadaíra, leg. 1094 PB, ff. 328r-329r.

29 Oficio de Silvestre de Montemayor, 11 de junio de 1503, 20 de junio de 1507 y 5 de octubre de 1507. AHPS, sección Protocolos, Alcalá de Guadaíra, leg. 1544 PB, s.f. 
administrador perpetuo del monasterio de Santa María de los Ángeles de Alcalá en el tercero:

- Cofradía de San Bartolomé ${ }^{30}$ : Martín Sánchez Navarro, Alonso Miguel del Castillo, Bartolomé López -bachiller-, Pedro Martínez de Dos Hermanas, Juan Sánchez Cumplido, Fernando de la Calzada, Alonso Fernández de Perales, Juan de la Milla, Juan Muñoz de la Gruesa, Alonso Martínez Tomé, Pedro Martínez Bondano, Alonso Blázquez, Antón García -labrador- y Gonzalo Martínez Galván.

- Cofradía de San Miguel ${ }^{31}$ : Andrés García-herrador-,Alonso Martínez de Mariserrana, Alonso Martínez de Maguilla, Juan Rodríguez de Mairena, Ruy Martínez Caro, Antón Sánchez de Mairena, Antón Martínez de Jaén, Diego Álvarez de Niebla, Juan Martínez de Ledesma, Marcos Sánchez de Marchenilla, Juan Blázquez de la calle Ancha y Juan Ponce.

- Cofradía de Santa Catalina ${ }^{32}$ : Juan Rodríguez de Mairena, Diego Martínez-hidalgo-, Diego Álvarez Moreno, Antón González, Antón Sánchez Retama, Francisco García de Torres, Juan Martínez de Ledesma, Juan Sánchez Perolucas, Alonso Martínez de Maguilla, Cristóbal Martínez de Cardeñosa, Domingo Martínez del Viso, Bartolomé Martínez de Bailén, Antón Rodríguez Benítez, Bartolomé Fernández Jarillo, Juan López de Feria, Fernando Martos Caballo y Alonso Martínez de Ledesma.

Como vemos, solamente se consignan los datos relativos a la titulación, profesión o pertenencia social de cuatro cofrades: un bachiller, un labrador, un herrador y un hidalgo. Nuevamente por datos indirectos podemos ampliar la información: Martín Sánchez Navarro era jurado del Concejo de Alcalá ${ }^{33}$; Pedro Martínez de Dos Hermanas, alcalde de la Santa Hermandad ${ }^{34}$; Alonso Blázquez, cortador en la carnicería alcalareña ${ }^{35}$; Ruy Martínez Caro, regidor del Concejo de Alcalá36; Diego Martínez, hidalgo, era mayordomo de la fábrica de la iglesia de San Miguel ${ }^{37}$; Cristóbal Martínez de Cardeñosa era mayordomo de la fábrica de la

30 Oficio de Silvestre de Montemayor, 20 de junio de 1507. AHPS, sección Protocolos, Alcalá de Guadaíra, leg. 1544 PB, s.f.

31 Oficio de Silvestre de Montemayor, 26 de septiembre de 1507. AHPS, sección Protocolos, Alcalá de Guadaíra, leg. 1544 PB, s.f.

32 Oficio de Silvestre de Montemayor, 5 de octubre de 1505. AHPS, sección Protocolos, Alcalá de Guadaíra, leg. 1544 PB, s.f.

33 Oficio de Silvestre de Montemayor, 25 de junio de 1503. AHPS, sección Protocolos, Alcalá de Guadaíra, leg. 1544 PB, s.f.

34 Oficio de Silvestre de Montemayor, 15 de marzo de 1506. AHPS, sección Protocolos, Alcalá de Guadaíra, leg. 1544 PB, s.f.

35 Oficio de Diego de Mairena, 30 de octubre de 1510. AHPS, sección Protocolos, Alcalá de Guadaíra, leg. 1094 PB, ff. 326v-328r.

36 Oficio de Diego de Mairena, 6 de mayo de 1509. AHPS, sección Protocolos, Alcalá de Guadaíra, leg. 1094 PB, ff. 12r-13r.

37 Oficio de Silvestre de Montemayor, 1 de marzo de 1506. AHPS, sección Protocolos, Alcalá de Guadaíra, leg. 1544 PB, s.f. 
iglesia de Santa María ${ }^{38}$. Aun siendo los datos muy escasos, apreciamos la presencia de miembros del sector primario (labrador), de profesiones liberales (bachiller, mayordomo) y del sector secundario de la economía (herrador, carnicero), que eran los que conformaban mayoritariamente las cofradías, especialmente estos últimos (Pérez González, 2005, pp. 142-151), además de miembros de las élites de la ciudad ${ }^{39}$. La dispersión de oficios nos permite afirmar para Alcalá lo que ya hizo para Sevilla la profesora Pérez González: nos encontramos ante un caso de evolución en el que las cofradías que nacieron vinculadas a un determinado oficio van abriendo sus puertas a miembros de otros sectores conforme se aproxima el fin de la Edad Media (Pérez González, 2005, pp. 142-151).

\section{LAS PROPIEDADES DE LAS COFRADÍAS}

Las cofradías bajomedievales basaron su economía principalmente en tres tipos de bienes: las casas, las propiedades rurales y el capital artesanal, todo ello procedente en la mayoría de las ocasiones de donaciones de personas que en su testamento legaban estos bienes a las corporaciones para que estas oficiaran determinados sufragios por sus almas o se encargaran de sus entierros (Pérez González, 2005, pp. 151-168). Nosotros hemos documentado los dos primeros casos. Con estos bienes las cofradías negociaban e incrementaban su patrimonio. Destacó sobre todo en los casos sevillano y jerezano la posesión de casas. El ganado, aunque escaso, también aparece como propiedad de algunas cofradías en Sevilla, algo que no sucede en Jerez (Pérez González, 2016). Los arrendamientos podían hacerse mediante la intervención del pregonero del concejo, que se encargaba de anunciar la puja, o bien directamente. Este fue el caso sevillano (Pérez González, 2005, p. 157), si bien en Jerez se dio solamente el negocio directo sin intervención del pregonero (Pérez González, 2016). También, para el caso de Sevilla se ha documentado en ocasiones la necesidad de permiso por parte de la autoridad eclesiástica para llevar a cabo este tipo de operaciones, lo que no sucedía en Jerez.

El trabajo del profesor Franco (Franco Silva, 1974) mencionaba las propiedades de dos de las cofradías alcalareñas: la de San Bartolomé (olivares, unas casas en la collación de San Sebastián y otras en la de Santiago) y la del Santo Espíritu (unas casas en la collación de Santiago y un olivar). La consulta de la documentación notarial alcalareña nos permite conocer algunos datos más.

38 Oficio de Silvestre de Montemayor, 24 de agosto de 1507. AHPS, sección Protocolos, Alcalá de Guadaíra, leg. 1544 PB, s.f.

39 Este es un dato significativo que no ha podido documentarse en los casos de Sevilla o Jerez al no mencionarlo directamente los documentos relacionados con las cofradías. En el caso de Alcalá, la menor proporción documental permite rastrear indirectamente con más facilidad la vida de los cofrades para saber más datos sobre ellos. 
En cuanto a las casas, además de las dos cofradías mencionadas, también poseían este tipo de propiedades las cofradías del Cuerpo de Dios y de Santa Catalina. Analicemos cada uno de los casos:

- Cofradía de San Bartolomé: el 21 de junio de 1507, la cofradía toma posesión de unas casas de su pertenencia en la collación de Santiago y que fueron morada de Alonso Pérez y su mujer ${ }^{40}$. En septiembre del mismo año, la cofradía anuncia mediante pregonero el arrendamiento de otras casas que posee en la collación de San Sebastián. Tras la puja se las adjudica Juan Fernández por 1100 maravedís al año. Unos días después se firma el contrato de arrendamiento por todos los días de la vida del nuevo inquilino, su mujer, o el heredero que estos nombrasen en testamento ${ }^{41}$.

- Cofradía del Santo Espíritu: el 24 de julio de 1508 la cofradía firma el contrato de arrendamiento de unas casas de su propiedad en la collación de Santiago a Pedro Martínez Notario, clérigo, por una vida y 880 maravedís al año a pagar en la fiesta de Todos los Santos. En las mismas casas habitaba otro clérigo, Nicolás Rodríguez, ya difunto ${ }^{42}$.

- Cofradía del Cuerpo de Dios: el 1 de junio de 1478, el bachiller Sancho Ruiz se desobliga del remate de unas casas propiedad de la cofradía en la collación de Santa María por ocho años y 750 maravedís anuales, ya que no se las entregaron reparadas ${ }^{43}$. El 30 de agosto del mismo año la cofradía arrienda las casas a Cosme de la Palera por cinco años y 600 maravedís anuales ${ }^{44}$.

- Cofradía de Santa Catalina: el 8 de enero de 1506, fray Vergalio de Espinosa, fraile de San Francisco y administrador perpetuo del monasterio de Santa María de los Ángeles de Alcalá ${ }^{45}$, reconoce la donación de unas casas que le fue hecha por parte de la cofradía ${ }^{46}$. En dichas casas construye un emparedamiento para freilas de la Tercera orden de San Francisco ${ }^{47}$.

40 Oficio de Silvestre de Montemayor, 21 de junio de 1507. AHPS, sección Protocolos, Alcalá de Guadaíra, leg. 1544 PB, s.f.

41 Oficio de Silvestre de Montemayor, 12 de septiembre de 1507 y ss. AHPS, sección Protocolos, Alcalá de Guadaíra, leg. 1544 PB, s.f.

42 Oficio de Silvestre de Montemayor, 24 de julio de 1508. AHPS, sección Protocolos, Alcalá de Guadaíra, leg. 1544 PB, s.f.

43 Oficio de Fernando García de Trigueros, 1 de junio de 1478. AHPS, sección Protocolos, Alcalá de Guadaíra, leg. 1544 PB, s.f.

44 Oficio de Fernando García de Trigueros, 30 de agosto de 1478. AHPS, sección Protocolos, Alcalá de Guadaíra, leg. 1544 PB, s.f.

45 Oficio de Silvestre de Montemayor, 5 de octubre de 1505. AHPS, sección Protocolos, Alcalá de Guadaíra, leg. 1544 PB, s.f.

46 Oficio de Silvestre de Montemayor, 8 de enero de 1506. AHPS, sección Protocolos, Alcalá de Guadaíra, leg. 1544 PB, s.f.

47 Oficio de Silvestre de Montemayor, 31 de julio de 1506. AHPS, sección Protocolos, Alcalá de Guadaíra, leg. 1544 PB, s.f. 
La documentación no nos aporta información sobre las características o dimensiones de las casas ni sobre la forma de adquisición de estas por parte de las cofradías, aunque suponemos, por analogía con los casos sevillano y jerezano (Pérez González, 2005, p. 152; 2016), que la principal vía de acceso a ellas fue por donación y no por compra, aunque esta pudiera darse en algunos casos. Las cofradías negociaban con estas casas principalmente mediante arrendamientos por una o varias vidas o, en algunos casos, por un tiempo menor (cinco años). Solamente documentamos un caso en el que la cofradía se desprende de sus casas a modo de donación para que estas puedan ser usadas para otro fin, en concreto la construcción de un emparedamiento.

Con respecto a la cuantía de las rentas, que se pagaban siempre en metálico, estas eran variables y dependerían con probabilidad de las características de los inmuebles o de su situación dentro de la ciudad. A veces estas rentas se cobraban en fechas en las que con probabilidad las cofradías necesitaban dinero para celebrar sus fiestas o las honras fúnebres de los cofrades o encomendados, como el día de Todos los Santos, fecha muy significativa por ser el mes de noviembre el dedicado a los difuntos.

Otro aspecto que podemos reseñar es el hecho de haber documentado negocios mediante anuncio por el pregonero y negocios directos, al igual que sucedía en Sevilla y a diferencia de Jerez de la Frontera, como ya hemos visto anteriormente. Una vez más la proximidad a la capital se hace patente en este tipo de analogías. No obstante, no hemos encontrado referencias a permisos de la autoridad eclesiástica, al igual que tampoco se han documentado en Jerez. Quizá esto pueda deberse a que la mayor lejanía con respecto a la sede diocesana fuera sinónimo de un menor control por parte de la autoridad eclesiástica.

Por último, algunas cofradías poseían también censos (Ballester Martínez, 2005-2006) sobre bienes inmuebles. Entendemos por censo las rentas sobre un determinado bien que recibe una persona -la propietaria del censo- que no es necesariamente la propietaria del citado bien. Los censos eran objeto de negocio y podían ser comprados y vendidos. Era el caso de la cofradía del Santo Espíritu, que el 13 de julio de 1503 compra a Juan de Carmona y Catalina Martínez un censo de 1000 maravedís de tributo perpetuo sobre unas casas de su morada en la collación de San Sebastián ${ }^{48}$. A efectos prácticos este tipo de operaciones funcionaban como una especie de préstamo mediante el cual el propietario obtenía liquidez y el comprador estaba realizando un desembolso importante pero que recuperaría posteriormente con el cobro anual del censo.

48 Oficio de Silvestre de Montemayor, 13 de julio de 1503. AHPS, sección Protocolos, Alcalá de Guadaíra, leg. 1544 PB, s.f. 
Con respecto al segundo grupo de bienes, el de las propiedades rurales y el ganado, también las cofradías alcalareñas contaron con ellos como parte importante de su economía. Documentamos olivares y colmenas:

- Cofradía de San Bartolomé: el 12 de septiembre de 1507 se pregona el arrendamiento por tres vidas de los olivares de la cofradía, siendo adjudicados finalmente por 550 maravedís anuales ${ }^{49}$. El día 19 del mismo mes y año se pregona nuevamente el arrendamiento de otros olivares pertenecientes a la misma cofradía, siendo en este caso adjudicados por 790 maravedíes $^{50}$. Sabemos que uno de estos olivares se situaba en el pago de Benaborra ${ }^{51}$.

- Cofradía del Santo Espíritu: sabemos que la cofradía contaba en 1508 con un olivar en el camino de Dos Hermanas ya que se menciona como linde de otro terreno objeto de negocio en un protocolo ${ }^{52}$.

- Cofradía de Santa María de la Candelaria: esta cofradía poseía varias colmenas (Carmona Ruiz, 2000) que fueron objeto de numerosos negocios. En febrero de 1503 se pregona el arrendamiento de varios grupos de colmenas, siendo adjudicado el primer grupo (sin especificar número) por un real anual cada una y el segundo (formado por 37 colmenas) por 32 maravedís anuales cada una durante tres años ${ }^{53}$. El 29 de marzo del mismo año se arriendan más colmenas, siendo adjudicadas por 20 maravedís cada una ${ }^{54}$. Por documento fechado el 2 de abril de ese año conocemos que Juan Martínez de la Gruesa el mozo poseía otra colmena de la cofradía a 32 maravedís anuales, anunciando su intención de devolverla a final de año ${ }^{55}$. El mismo día se produce un nuevo pregón de arrendamiento de colmenas, siendo adjudicadas también por 32 maravedís $^{56}$. Unos años más tarde, en marzo de 1510, documentamos un nuevo pregón de arrendamiento, siendo adjudicadas las colmenas por 31 maravedís anuales cada una ${ }^{57}$. Ese mismo mes encontramos un contrato de arrendamiento sin pregón

49 Oficio de Silvestre de Montemayor, 12 de septiembre de 1507. AHPS, sección Protocolos, Alcalá de Guadaíra, leg. 1544 PB, s.f.

50 Oficio de Silvestre de Montemayor, 19 de septiembre de 1507. AHPS, sección Protocolos, Alcalá de Guadaíra, leg. 1544 PB, s.f.

51 Oficio de Silvestre de Montemayor, 15 de noviembre de 1508. AHPS, sección Protocolos, Alcalá de Guadaíra, leg. 1544 PB, s.f.

52 Oficio de Silvestre de Montemayor, 16 de marzo de 1508. AHPS, sección Protocolos, Alcalá de Guadaíra, leg. 1544 PB, s.f.

53 Oficio de Silvestre de Montemayor, 11 y 19 de febrero de 1503. AHPS, sección Protocolos, Alcalá de Guadaíra, leg. 1544 PB, s.f.

54 Oficio de Silvestre de Montemayor, 29 de marzo de 1503. AHPS, sección Protocolos, Alcalá de Guadaíra, leg. 1544 PB, s.f.

55 Oficio de Silvestre de Montemayor, 2 de abril de 1503. AHPS, sección Protocolos, Alcalá de Guadaíra, leg. 1544 PB, s.f.

56 Oficio de Silvestre de Montemayor, 2 de abril de 1503. AHPS, sección Protocolos, Alcalá de Guadaíra, leg. 1544 PB, s.f.

57 Oficio de Diego de Mairena, 10 de marzo de 1510. AHPS, sección Protocolos, Alcalá de Guadaíra, leg. 1094 PB, ff. 171v-172r. 
previo por el que se alquilan 22 colmenas durante tres años a razón de 30 maravedíes anuales cada una, a pagar el día de Santa María de Agosto ${ }^{58}$. Desconocemos la cantidad total de colmenas que poseía la cofradía, pero por los diversos movimientos protagonizados por ellas suponemos que eran una fuente principal de ingresos para la corporación.

Como sucedía con el caso de los bienes inmuebles, estas propiedades eran arrendadas por las cofradías para obtener rentas, bien mediante pregón o directamente con la persona interesada, al igual que en el caso sevillano. Los arrendamientos solían hacerse siempre en metálico y por largos períodos, como tres vidas, en el caso de los terrenos; o intervalos más pequeños, como tres años, en el de las colmenas (Borrero Fernández, 1998; 2003). Según el profesor Franco (Franco Silva, 1974), las condiciones impuestas por las cofradías para realizar los arrendamientos, especialmente los de tierras, eran que el arrendador tuviera bien labrados los olivares, que permitiera a los cofrades visitar los terrenos cada año o que no pudiera traspasarlos sin permiso de la cofradía.

También se dio la situación de cofradías que no eran propietarias de las tierras sino de las rentas asociadas a ellas, como la del Cuerpo de Dios que en julio de 1503 demanda las cantidades que le corresponden sobre unas tierras cuyas rentas donó a la cofradía Llorente Martínez en su testamento ${ }^{59}$.

\section{GONGLUSIONES}

La consulta de la documentación notarial para el estudio de las cofradías alcalareñas bajomedievales se revela de gran utilidad a pesar de la relativa escasez de datos que proporcionan estos documentos, sobre todo en comparación con otras localidades. Aun así, la investigación permite llenar huecos aún existentes en la historiografía local y poner en relación los datos obtenidos con otros estudios sobre las cofradías en otros puntos del Reino de Sevilla, lo que supone un enriquecimiento notable para un tema que aún permite muchas posibilidades de investigación.

Los protocolos nos dan cuenta de la inserción de las cofradías dentro de la vida social de la localidad en la que se ubicaban. Como parte importante de la sociedad alcalareña, estas corporaciones agruparon a numerosos vecinos de la villa, particularmente aquellos dedicados al sector secundario de la economía y los vinculados con las élites de gobierno del municipio. Para poner en marcha el amplio programa de cultos -particularmente honras fúnebres (Arboleda Goldaracena, 2014)- y actividades -sobre todo aquellas relacionadas con el plano benéficoasistencial (Arboleda Goldaracena, 2013; 2015; Lozano y Torremocha, 2013)- que

58 Oficio de Diego de Mairena, 25 de marzo de 1510. AHPS, sección Protocolos, Alcalá de Guadaíra, leg. 1094 PB, ff. 182r-183r.

59 Oficio de Silvestre de Montemayor, 3 y 24 de julio de 1503. AHPS, sección Protocolos, Alcalá de Guadaíra, leg. 1544 PB, s.f. 
desarrollaban, las cofradías tuvieron que sentar sus bases económicas en la posesión de determinados bienes inmuebles y propiedades rurales con los que negociaron para obtener beneficios, principal motivo de su presencia en la documentación notarial.

En muchos de los aspectos estudiados, vemos una correspondencia directa de lo que sucedía en Alcalá con lo expuesto en investigaciones previas sobre el caso de la capital sevillana, tanto en las preferencias devocionales de las cofradías como en su composición social, sus órganos de gobierno o sus actividades económicas. Y esto se explica por la estrecha relación entre la villa alcalareña y la urbe que le era tan próxima. Ya desde la conquista de ambos términos, Alcalá se convirtió en una puerta segura de acceso a la ciudad hispalense y en un bastión importante para su defensa. Numerosos terrenos dentro del territorio de Alcalá fueron entregados a habitantes de Sevilla, y además la propia villa alcalareña fue durante buena parte del período finimedieval propiedad de la Iglesia hispalense. La identificación entre ambas ciudades es evidente, y estudiar cualquier aspecto religioso y social de Alcalá implica completar o comprender mejor todo lo que ya se ha estudiado sobre Sevilla.

Por desgracia, los protocolos notariales son prácticamente la única fuente disponible para conocer las cofradías existentes en Alcalá a finales de la Edad Media. Ya hemos indicado que no se ha hallado hasta el momento otro tipo de documentación más directa producida por ellas mismas, como pudieran ser sus reglas o los libros de registros de hermanos o acuerdos de cabildos, que nos permitirían conocer más datos de su vida interna (características de sus hermanos, cultos que celebraban, actividades benéficas que desarrollaban...). Todo ello comienza a aflorar muy a finales del Quinientos, momento desde el cual la documentación se hace mucho más abundante. Aun así, los protocolos sí que permiten seguir indagando el interesantísimo siglo XVI, momento clave para entender la evolución de las cofradías que poco a poco van a ir virando desde corporaciones plenamente medievales a instituciones instaladas en la modernidad y la mentalidad barroca.

\section{BIBLIOGRAFÍA}

Arboleda Goldaracena, Juan Carlos (2012). El gobierno de las hermandades y cofradías andaluzas en la Baja Edad Media. En: Arizaga Bolumburu, Beatriz et alii (coord.), Mundos medievales: espacios, sociedades y poder. Homenaje al Profesor José Ángel García de Cortázar y Ruiz de Aguirre. Santander: Universidad de Cantabria, vol. 2, pp. 1005-1014.

Arboleda Goldaracena, Juan Carlos (2013). La caridad en la historia del cristianismo: algunas manifestaciones en la Andalucía bajomedieval. Medievalista, n. 14, disponible en: http://www2.fcsh.unl.pt/iem/medievalista/MEDIEVALISTA14/ goldaracena1403.html [Última consulta: 7 de junio de 2017]

Arboleda Goldaracena, Juan Carlos (2014). Los laicos y su actitud ante la muerte en la Sevilla de la Baja Edad Media y los comienzos de la modernidad. En Miura 
Andrades, José María (dir.) y Arboleda Goldaracena, Juan Carlos (coord.), Lágrimas en la lluvia. Estudios sobre la muerte y los muertos. Sevilla: Aconcagua, pp. 291-300.

Arboleda Goldaracena, Juan Carlos (2015). La práctica de la doctrina cristiana en las cofradías de Sevilla durante la Baja Edad Media y los comienzos de la modernidad. En Roda Peña, José (dir.), XVI Simposio sobre Hermandades de Sevilla y su provincia. Sevilla: Fundación Cruzcampo, pp. 15-40.

Arboleda Goldaracena, Juan Carlos (2016). Creencias y devociones en las cofradías sevillanas de finales de la Edad Media y comienzos de la modernidad. Revista de Humanidades, n. 29, pp. 9-36.

Ballester Martínez, Adolfo (2005-2006). Los censos: concepto y naturaleza. Espacio, tiempo y forma. Serie IV, Historia Moderna, n. 18-19, pp. 35-50.

Borrero Fernández, Mercedes (1998). Protocolos notariales y mundo rural: los contratos agrarios como fuente para el estudio de la vida campesina en Andalucía occidental en la Baja Edad Media. En Ostos Salcedo, Pilar y Pardo Rodríguez, María Luisa, En torno a la documentación notarial y a la historia. Sevilla: Ilustre Colegio Notarial, pp. 83-96.

Borrero Fernández, Mercedes (2003). Mundo rural y vida campesina en la Andalucía medieval, Granada: Universidad de Granada.

Carmona Ruiz, María Antonia (2000). La apicultura sevillana a fines de la Edad Media. Anuario de Estudios Medievales, n. 30/1, pp. 131-154.

FernándezGómez,Marcos(2004).NuevosdatosydocumentossobrelarepoblacióndeAlcalá de Guadaíra (1280-1335). Historia. Instituciones. Documentos, n. 31, pp. 167-191.

Fernández Gómez, Marcos (2007). La fundación de Alcalá de Guadaíra: estudio crítico de la Carta Puebla de 1280. Alcalá de Guadaíra: IES Albero.

Flores, Leandro José de (1833). Memorias históricas de la villa de Alcalá de Guadaíra. Sevilla. Edición facsímil (Mairena del Aljarafe, 2008).

Franco Silva, Alfonso (1974). La propiedad de eclesiásticos de Alcalá de Guadaíra a fines de la Edad Media. Historia. Instituciones. Documentos, n. 1, pp. 75-84.

Franco Silva, Alfonso (1987). Alcalá de Guadaíra en los siglos XIV y XV: población, economía y sociedad. En VV.AA., Actas de las I Jornadas de Historia de Alcalá de Guadaíra. Alcalá de Guadaíra: Ayuntamiento de Alcalá de Guadaíra, pp. 53-58.

Franco Silva, Alfonso (1995). La Edad Media (siglos XIII-XVI). En Rodríguez Baltanás, Enrique (dir.), Alcalá de Guadaíra: pasado, presente y futuro. Alcalá de Guadaíra: Ayuntamiento de Alcalá de Guadaíra, pp. 69-82.

García Díaz, Jesús (2010). Los más antiguos protocolos notariales de Alcalá de Guadaíra (1478-1510). Sevilla: Diputación Provincial.

García Martínez, Antonio Claret (1998). Alcalá de Guadaíra en las crónicas castellanas medievales. En: VV.AA., Actas de las V Jornadas de Historia de Alcalá de Guadaíra. Alcalá de Guadaíra: Ayuntamiento de Alcalá de Guadaíra. 
García Martínez, Antonio Claret (2000a). Alcalá de Guadaíra: de la media luna a la cruz. En García Mora, Antonio (ed.), Ecos de la historia de Alcalá de Guadaíra. Alcalá de Guadaíra: Biblioteca de textos alcalareños, pp. 27-29.

García Martínez, Antonio Claret (2000b). Estructuras sociales en la Edad Media. Las relaciones de vasallaje entre musulmanes y cristianos: el caso de Alcalá de Guadaíra. En García Mora, Antonio (ed.), Ecos de la historia ... ob. cit., pp. 31-33.

García Rivero, Francisco (1997). Orígenes e historias de Alcalá de Guadaíra. Alcalá de Guadaíra: Ayuntamiento de Alcalá de Guadaíra.

González Jiménez, Manuel (1987). Alcalá de Guadaíra en el siglo XIII. Anales de la Universidad de Alicante. Historia Medieval, n. 6, pp. 135-158.

González Moreno, Joaquín (1986). Aportación a la historia de Alcalá de Guadaíra. Alcalá de Guadaíra. Ayuntamiento de Alcalá de Guadaíra.

Jiménez Rodríguez, Javier (2000). Algunos aspectos de la morfología urbana de Alcalá según un texto de 1482. En García Mora, Antonio (ed.), Ecos de la historia ... ob. cit., pp. 43-44.

Lozano Ruiz, Carlos y Torremocha, Margarita (2013). Asistencia social y cofradías en el Antiguo Régimen. Historiografía, líneas de investigación y perspectivas. Chronica Nova, n. 39, pp. 19-46.

Martín-Viveros Tajuelo, Antonio (2012). Las cofradías castellanas en la Edad Media. Pasado, presente y futuro de la producción historiográfica. Espacio, Tiempo y Forma. Serie III. Historia Medieval, t. 25, pp. 285-308.

Navarro Espinach, Germán (2014). Las cofradías medievales en España. Historia 396, $\mathrm{n}^{\mathrm{o}} 1$, pp. 107-133.

Pérez González, Silvia María (2003). La presencia de las cofradías en la fiesta del Corpus Christi en Sevilla a finales del siglo XV y comienzos del XVI. Boletín de las Cofradias de Sevilla, n. 532, pp. 450-451.

Pérez González, Silvia María (2005). Los laicos en la Sevilla bajomedieval: sus devociones y cofradías. Huelva: Universidad de Huelva.

Pérez González, Silvia María (2006). Los santos venerados en Sevilla en el siglo XV y principios del XVI. En Vitse, Marc (coord.), Homenaje a Henri Guerreiro: la hagiografia entre historia y literatura en la España de la Edad Media y del Siglo de Oro. Madrid: Iberoamericana, pp. 985-997.

Pérez González, Silvia María (2016). Nuevas aportaciones al estudio de las cofradías y hermandades en la Castilla bajomedieval: el ejemplo de Jerez de la Frontera. Hispania Sacra, vol. 68, n. 138, pp. 503-520.

Pérez González, Silvia María y Arboleda Goldaracena, Juan Carlos (2017). CXXII Reglas de Hermandades y Cofradías Andaluzas. Siglos XVI y XVII. Huelva: Universidad de Huelva. 
Rodríguez Baltanás, Enrique (1999). El proceso ermita-parroquia-santuario: el caso de Santa María del Águila en Alcalá de Guadaíra. En Rodríguez Becerra, Salvador (coord.), Religión y cultura. Sevilla: Fundación Machado, vol. 2, pp. 125-128.

Romero Abao, Antonio (1989). La fiesta del Corpus Christi en Sevilla en el siglo XV. En Álvarez Santaló, Carlos et al., La religiosidad popular. Barcelona: Anthropos, vol. III, pp. 19-29.

Romero Gutiérrez, Vicente (2001). La iglesia de San Miguel. Escaparate, Navidad 2001, pp. 33-40.

Ruiz Portillo, Enrique (2011). La parroquia de Santiago el mayor de Alcalá de Guadaíra: estudio histórico-artístico. Sevilla: Diputación Provincial.

Sánchez Herrero, José (1985). Las cofradías sevillanas. Los comienzos. En Sánchez Herrero, José et al. (eds.), Las cofradías de Sevilla: historia, antropología, arte. Sevilla: Universidad de Sevilla, pp. 9-34.

Sánchez Herrero, José (1988). Las cofradías de Semana Santa de Sevilla durante la modernidad. Siglos XV a XVII. En Sánchez Mantero, Rafael et al. (eds.), Las cofradias de Sevilla en la modernidad. Sevilla: Universidad de Sevilla, pp. 27-88.

Sánchez Herrero, José (1989). Algunos elementos de la religiosidad cristiana popular andaluza durante la Edad Media. En Álvarez Santaló, Carlos et al., La religiosidad..., ob.cit., vol.1, pp. 268-307.

Sánchez Herrero, José (1992). El lánguido mantenimiento de unas reformas religiosas. 1433-1474. En Ros, Carlos (dir.), Historia de la Iglesia de Sevilla. Sevilla: Castillejo, pp. 243-299.

Sánchez Herrero, José (1995). El origen de las cofradías penitenciales. En VV.AA. (eds.), Sevilla Penitente. Sevilla: Gever, vol. I, pp. 13-55.

Sánchez Herrero, José (1996). El origen de las cofradías de Semana Santa o de Pasión en la Península Ibérica. Temas Medievales, n. 6, pp. 31-79.

Sánchez Herrero, José (1999). Piedad y artes plásticas. La devoción a la Preciosa Sangre de Cristo durante los siglos XIII a los primeros años del XVI y su influencia en las manifestaciones artísticas. En Actas do Colóquio Internacional: Piedade popular. Sociabilidades-Representaçoes-Espiritualidades. Lisboa: Terramar, pp. 411-432.

Sánchez Herrero, José (2003). La Semana Santa de Sevilla. Madrid: Sílex.

Sánchez Herrero, José (en línea). La evolución de las hermandades y cofradías desde sus momentos fundacionales hasta nuestros días. En: Consejo General de Hermandades y Cofradias de la Ciudad de Sevilla, disponible en: <http://www.hermandades-desevilla.org/hermandades/historia-de-las-hermandades-y-cofradia/introduccion> [Última consulta: ${ }^{\circ}$ de junio de 2017]

Sánchez Herrero, José y Pérez González, Silvia María (1999). La Cofradía de la Preciosa Sangre de Cristo de Sevilla. La importancia de la devoción a la Preciosa Sangre de Cristo en el desarrollo de la devoción y la imaginería de la Semana Santa. Aragón 
en la Edad Media. Homenaje a la profesora Carmen Orcástegui Gros, nn. 14-15, pp. 1429-1452.

Sánchez Herrero, José y Pérez González, Silvia María (2002). CXIX Reglas de Hermandades y Cofradias andaluzas. Siglos XIV, XV y XVI. Huelva: Universidad de Huelva.

Rodríguez Mateos, Joaquín y López Gutiérrez, Antonio José (2000). Archivos y documentos en las hermandades sevillanas. Sevilla: Castillejo. 
